\title{
Clinical efficacy of modified total auricular reconstruction technique by using reformative inflation method and remnant ear without skin grafting
}

\author{
Yingyi Zhang" ${ }^{1 \#}$, Chuanqi Liu" ${ }^{1 \#}$, Shiyou Wei ${ }^{2}$, Guonian Zhu' ${ }^{3}$ Zhengyong Li $^{1}$ \\ ${ }^{1}$ Department of Plastic Surgery and Burns, West China Hospital, Sichuan University, Chengdu, China; ${ }^{2}$ Department of Thoracic Surgery, West \\ China Hospital, Sichuan University, Chengdu, China; ${ }^{3}$ Research Core Facility, West China Hospital, Sichuan University, Chengdu, China \\ Contributions: (I) Conception and design: Y Zhang; (II) Administrative support: Z Li; (III) Provision of study materials or patients: Z Li; (IV) \\ Collection and assembly of data: Y Zhan, C Liu; (V) Data analysis and interpretation: C Liu, S Wei, G Zhu; (VI) Manuscript writing: All authors; (VII) \\ Final approval of manuscript: All authors. \\ "These authors contributed equally to this study. \\ Correspondence to: Zhengyong Li, MD. Department of Plastic Surgery and Burns, West China Hospital, Sichuan University, No. 37 Guo Xue Xiang, \\ Chengdu 610041, China. Email: 302992694@qq.com.
}

\begin{abstract}
Background: As one of the most widely used methods to treat microtia, the auricular reconstruction proposed by Zhuang may have several drawbacks. This study aimed to introduce a modified Zhuang's ear reconstruction technique by using a reformative inflation method and remnant ear to shorten therapy time and avoid skin grafting in a two-stage operation for patients with microtia.
\end{abstract}

Methods: A total of 124 patients with microtia were enrolled consecutively from 2014 to 2018. Among them, 66 patients underwent a modified Zhuang's method, and the remaining patients underwent Zhuang's method. The clinical and perioperative characteristics of patients, as well as complications and esthetic outcomes were analyzed.

Results: Compared with Zhuang's group, our modified Zhuang's group had better average esthetic scores according to two plastic surgeons [11.5 (IQR, 10.5-12.5) vs. 9.5 (IQR, 7.5-11.0), $\mathrm{P}<0.001$ ], fewer hypertrophic scar cases $[0 \%(\mathrm{n}=0 / 66)$ vs. $10 \%(\mathrm{n}=6 / 58), \mathrm{P}=0.024]$, shorter whole therapy duration [2.5 (IQR, 2.4-2.6) vs. 5.0 (IQR, 5.0-5.1) days, $\mathrm{P}<0.001]$ and shorter hospital duration after operation $[5$ (IQR, 5-6) vs. $6(\mathrm{IQR}, 5-6)$ days, $\mathrm{P}=0.013]$.

Conclusions: Our modified Zhuang's technique is a new method to treat microtia which results in a clear contour of the reconstructed ear and matching skin color, minimal scarring, and a short treatment time.

Keywords: Microtia; auricular reconstruction; skin grafting; remnant ear; tissue expander

Submitted Feb 24, 2021. Accepted for publication May 13, 2021.

doi: 10.21037/atm-21-1302

View this article at: http://dx.doi.org/10.21037/atm-21-1302

\section{Introduction}

Microtia is a congenital external ear deformity occurring in about one in every 5,000 births (1) and can affect both the appearance and mental health of patients (2-4). There is currently no consensus concerning the pathogenesis and etiology of microtia. Total auricular reconstruction remains the primary treatment for microtia (5), and is a great challenge for plastic surgeons globally. The skin envelope and the three-dimensional framework are two eternal themes of auricular reconstruction (6). In addition to the pursuit of a more delicate and lifelike 3D ear framework, many surgeons are still working on tissue coverage techniques to achieve satisfying results with few complications.

The first report of tissue expansion applied to auricular reconstruction appeared in the 1950's. Later, Park et al. (7-9) 
developed the two-flap method using a tissue expander and autogenous costal cartilage, and this has become the current mainstream method of auricular reconstruction using tissue expander in Asia. However, this method relies on skin grafting, which can lead to scarring, unmatched color, and hypertrophic scarring, which are more prominent in Asian patients (10).

Xing et al. $(10,11)$ modified the auricular reconstruction technique by using a single expanded postauricular flap without skin grafting. However, these methods generally require 5-10 months to heal, which increases the risk of complications and the economic and psychological burden placed on patients and their families.

To establish a safer auricular reconstruction method resulting in better appearance, fewer complications, and involving less curative time, we have modified Zhuang's traditional pre-expansion auricular reconstruction (9) via using the reformative inflation method and remnant ear. This article details this modified method and systematically compares outcomes, including the final satisfaction of both patients and surgeons, clinical and perioperative characteristics, and the rate of complications between Zhuang's method and our modified method. We present the following article in accordance with the STROBE reporting checklist (available at http://dx.doi.org/10.21037/atm-211302).

\section{Methods}

A retrospective review of consecutive patients who underwent auricular reconstruction using tissue expander and autogenous costal cartilage from July 2014 to December 2018 at West China Hospital, Sichuan University by a single surgeon (Zhengyong Li) was performed. This study was approved by the ethics committee of Sichuan University [No.: 2020(680)], and all subjects or their parents/guardians gave informed consent before surgery. All procedures performed in this study involving human participants were in accordance with the Declaration of Helsinki (as revised in 2013). Patients treated with Zhuang's method were defined as Zhuang's group ( $n=58)$, whereas patients treated with our modified method were defined as the modified Zhuang's group ( $\mathrm{n}=66)$. In Zhuang's group, patients received auricular reconstruction described in detail in Zhuang's article (9). Our modified technique is presented in Figure 1 and is detailed below.

\section{First-stage period}

A $50 \mathrm{~mL}$ kidney-shaped expander was implanted in the mastoid area during the first-stage operation, and the expander insertion pocket was created in the subcutaneous layer to produce a clear outline of the three-dimensional auricular framework. Expander inflation began on the 14th day after surgery, while the sutures were removed simultaneously. Five milliliters of $0.9 \%$ sterile saline solution were then injected into each expander three times per week for 4-5 weeks, which could reach a volume of $60-75 \mathrm{~mL}$ and result in satisfactory thickness and softness. Afterwards, the same amount of sterile saline solution was injected once per week for 4 weeks, which could avoid expanded flap retraction while expanding moderately. Patients then took a rest of 2 weeks after our modified inflation method. The whole period between the first and second-stage lasted for approximately 2.5 months, which was shorter than the usual period of 5 months.

\section{Second-stage period}

The second-stage surgery began when the expanded flaps achieved a stable area, suitable thickness, and satisfactory softness (Figure 1A). First, a short incision at the lower part of the expanded flap and remnant ear was designed, where the expander was removed. When the expander was dissected and removed, we focused on the remnant auricular cartilage and redundant tissue, which could deepen the cavum conchae, rebuild a more realistic ear, and eliminate the need for third-stage surgery. Then, a modified three-dimensional cartilage framework in three layers (Figure $1 B, C, D$ ) which shows the cartilage we removed and the detailed structure of the three-dimensional framework) was inserted into the envelope and fixed at an appropriate position based on the marking lines. When suction was applied, the outline of the reconstructed ear was immediately apparent (Figure 1E). During this period, the expander capsule was reserved to provide proper thickness and avoid framework exposure. Finally, the remnant tissue and auricular cartilage were used for rebuilding the earlobe and the tragus. Other remnant tissue was dissected under the premise of leaving no incision tension, and full-thickness suture using 7-0 Prolene was applied to all incisions. The level of negative pressure for the suction was regulated based on the blood supply of the flaps and the outline of the 



Figure 1 Intraoperative photographs showing operative procedures using our reformative inflation method and remnant ear without skin grafting. (A) Implantation of tissue expander which has reached ideal inflation, and the incision design of the second stage; (B) harvested seventh, eighth, and sixth costal cartilages; (C) modified three-dimensional cartilage framework in three layers; (D) landmarks of the helix, antihelix, scaphe, and triangular fossa were reconstructed in the cartilage framework; (E) outline of the reconstructed ear was immediately apparent when suction was applied.

reconstructed ear. Afterwards, erythromycin ointment and gauze coverage were applied. The suction appliance could be removed on the fifth day after surgery and the antibiotic used was second-generation cephalosporin, which was administered $30 \mathrm{~min}$ before surgery and lasted for $48 \mathrm{~h}$.

Electronic medical records and preoperativeintraoperative-postoperative photographs were reviewed.
Data regarding the clinical characteristics of patients, duration of the second-stage surgery, amount of bleeding, amount of drainage, hospital duration after operation, and medical complications were collected. Any complication in both recipient and donor site that required intervention at any time postoperatively was considered. The postoperative photographs of each patient were evaluated and scored 
Table 1 Scoring system of reconstructed ears

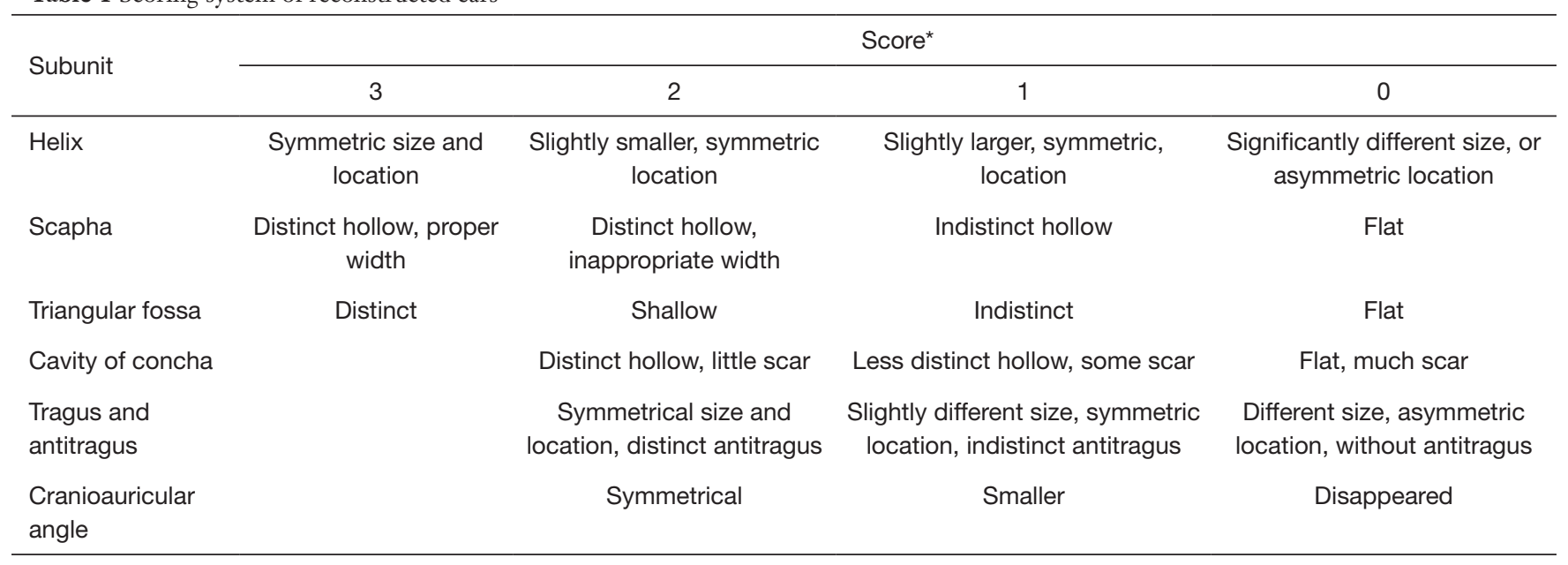

*, an excellent rate was defined as a total score of 10 to 15 , a good rate was defined as 6 to 9 , and a bad rate was defined as 0 to 5 (12).

based on an acknowledged evaluation criterion for the outcome of ear reconstruction (Table 1) by two plastic surgeons. An excellent rate was defined as a total score of 10 to 15 , a good rate was defined as 6 to 9 , and a bad rate was defined as 0 to 5 (12).

\section{Statistical analysis}

Continuous normal data were expressed as mean values \pm standard deviation, whereas continuous non-normal data were presented as medians with interquartile ranges (IQRs). Categorical data were presented as counts and percentages and differences between Zhuang's group and the modified Zhuang's group were evaluated using Student's $t$ test for continuous normal variables, Mann-Whitney $U$ test for continuous non-normal data variables, and chi-square analysis or the Fisher's exact test for the categorical data variables. Statistical analyses were performed using SPSS Statistics version 22 (IBM Corporation, Armonk, New York, USA) and GraphPad Prism version7 (GraphPad Software Inc., San Diego, California, USA). A P value $<0.05$ was considered statistically significant.

\section{Results}

The general clinical profiles of patients are presented in Table 2. The baseline characteristics of patients were comparable between the two groups, including age [13.8 (IQR, 8.1-18.0) vs. 10.9 (IQR, 8.0-18.5) years, $\mathrm{P}=0.447$ ], weight [45.5 (IQR, 27.5-53.0) vs. 36.5 (IQR, 24.8-51.8) kg,
$\mathrm{P}=0.284]$, and water injection [70.0 (IQR, 67.3-71.0) vs. 70.0 (IQR, 70.0-85.0) mL, $\mathrm{P}=0.071]$. No significant difference was found in the constituent ratios of hemifacial microsomia [34\% $(\mathrm{n}=20 / 58)$ vs. $23 \%(\mathrm{n}=15 / 66), \mathrm{P}=0.147]$, hearing disorders $[60 \%(\mathrm{n}=35 / 58)$ vs. $53 \%(\mathrm{n}=35 / 66), \mathrm{P}=0.412]$, size of vestige $(\mathrm{P}=0.552)$, and microtia ear side $(\mathrm{P}=0.194)$.

The median follow-up time was 34 (IQR, 26-61) months, ranging from 18 months to 71 months (more than at least one year). One case of the Zhuang's group (1/58) and three cases of our modified Zhuang's group (3/66) refused to provide postoperative photographs during the follow-up and were lost to follow-up (the lost rate of follow up was $1.7 \%$ and $4.5 \%$, respectively) of the postoperative esthetic outcomes. The scores of postoperative esthetic outcomes (Table 3 and Figure 2) for our modified Zhuang's group were significantly higher than Zhuang's group $(\mathrm{P}<0.001)$. The average esthetic scores of the two plastic surgeons were 9.5 (IQR, 7.5-11.0) and 11.5 (IQR, 10.5-12.5) for Zhuang's group and modified Zhuang's group, respectively. The scores of each plastic surgeon also showed the same result $(\mathrm{P}<0.001)$. The median scores of Surgeon 1 were 10.0 (IQR, 7.0-11.0) and 11.0 (IQR, 11.0-12.0), whereas those of Surgeon 2 were 9.0 (IQR, 7.5-11.0) and 12.0 (IQR, 10.0-13.0) for both groups, respectively (for typical cases of modified Zhuang's group refer to Figures 3-5).

The complications of both groups are shown in Table 4. No severe complications such as infection, hematoma, skin necrosis, and atelectasis, were seen in either group during the whole procedure and followup and no significant difference was found in general 
Table 2 Patient basic characteristics

\begin{tabular}{|c|c|c|c|}
\hline Characteristic & Zhuang's group ( $n=58)$ & Modified Zhuang's group $(n=66)$ & $P$ value \\
\hline Male & $42[72]$ & $45[68]$ & \\
\hline Female & 16 [28] & $21[32]$ & \\
\hline Age (years) & $13.8[8.1-18.0]$ & $10.9[8.0-18.5]$ & 0.447 \\
\hline Disease duration (years) & $51[46-58]$ & 16 [11-22] & $<0.001$ \\
\hline Microtia ear side & & & $0.194^{\dagger}$ \\
\hline Left & $25[43]$ & $21[32]$ & \\
\hline Right & $33[57]$ & $45[68]$ & \\
\hline Operation history & $1[2]$ & $0[0]$ & $0.468^{\ddagger}$ \\
\hline Hearing disorders & $35[60]$ & $35[53]$ & $0.412^{\dagger}$ \\
\hline Hemifacial microsomia & 20 [34] & 15 [23] & $0.147^{\dagger}$ \\
\hline Size of vestige & & & 0.552 \\
\hline Anotia & 7 [12] & $7[11]$ & \\
\hline Small lobule but usable & $10[18]$ & 13 [20] & \\
\hline Normal lobule & $29[50]$ & 34 [51] & \\
\hline Concha type & $6[10]$ & $7[10]$ & \\
\hline
\end{tabular}

Data are shown as number [percentage] or median [IQR]. *, independent Samples Mann-Whitney U test. ${ }^{\dagger}$, Pearson Chi-Square test; ${ }^{\ddagger}$, Fisher's exact test.

complications $[17 \%(\mathrm{n}=10 / 58)$ vs. $8 \%(\mathrm{n}=5 / 66), \mathrm{P}=0.100]$. For detailed comparisons, no complications occurred in the first-stage period (inflation period) in both groups, while complications related to the second-stage period occurred on ten cases in Zhuang's group and five cases in the modified Zhuang's group [17\% ( $\mathrm{n}=10 / 58)$ vs. $8 \%(\mathrm{n}=5 / 66)$, $\mathrm{P}=0.100]$. To be more specific, complications related to the second-stage period were divided into complications of the recipient site and complications of the donor site. No significant difference was found in complications related to the donor site [7\% ( $\mathrm{n}=4 / 58)$ vs. $8 \%(\mathrm{n}=5 / 66), \mathrm{P}=1.000]$. However, complications of the recipient site showed a different profile with hypertrophic scarring occurring in six cases in the Zhuang's group while not occurring in the modified Zhuang's group [10\% $(\mathrm{n}=6 / 58)$ vs. $0 \%(\mathrm{n}=0 / 66)$,
$\mathrm{P}=0.024]$.

Compared with Zhuang's group, the modified Zhuang's group had a shorter whole therapy duration [2.5 (IQR, 2.4-2.6) vs. 5.0 (IQR, 5.0-5.1) days, $\mathrm{P}<0.001]$ and a shorter hospital duration after operation [5 (IQR, 5-6) vs. 6 (IQR, 5-6) days, $\mathrm{P}=0.013$ ] (Table 5), which was more time saving and economical for patients. In the preoperative period the modified Zhuang's group had less bleeding [20.0 (IQR, 13.5-48.5) vs. 50.0 (IQR, 20.0-50.0) $\mathrm{mL}, \mathrm{P}=0.001]$ and less drainage $(15.9 \pm 1.2$ vs. $21.2 \pm 12.6 \mathrm{~mL}, \mathrm{P}=0.011)$, which reflected a lower degree of operation trauma. However, our modified Zhuang's group had a longer surgery duration [180 (IQR, 180-215) vs. 170 (IQR, 165-190) min, $\mathrm{P}=0.010$ ] because of specific modeling of the ear subunit during the second stage. 
Table 3 Esthetic outcomes

\begin{tabular}{|c|c|c|c|}
\hline Esthetic scores & Zhuang's group $(n=57)$ & Modified Zhuang's group $(n=63)$ & $P$ value* \\
\hline Excellent rate $^{\dagger}$ & $30[52]$ & $51[81]$ & \\
\hline Good rate ${ }^{\ddagger}$ & $17[30]$ & $10[16]$ & \\
\hline Bad rate $\S^{\S}$ & $10[18]$ & 2 [3] & \\
\hline Excellent rate & $27[47]$ & $52[82]$ & \\
\hline Good rate & $25[44]$ & $10[16]$ & \\
\hline Bad rate & 5 [9] & 1 [2] & \\
\hline Average & $9.5[7.5-11.0]$ & $11.5[10.5-12.5]$ & $<0.001$ \\
\hline Bad rate & $5[9]$ & 1 [2] & \\
\hline
\end{tabular}

Data are shown as number [percentage] or median [IQR]. *, independent samples Mann-Whitney $U$ test. ${ }^{\dagger}$, excellent rate $10-15$; ${ }^{\ddagger}$, good rate $6-9 ;{ }^{\S}$, bad rate $0-5$.

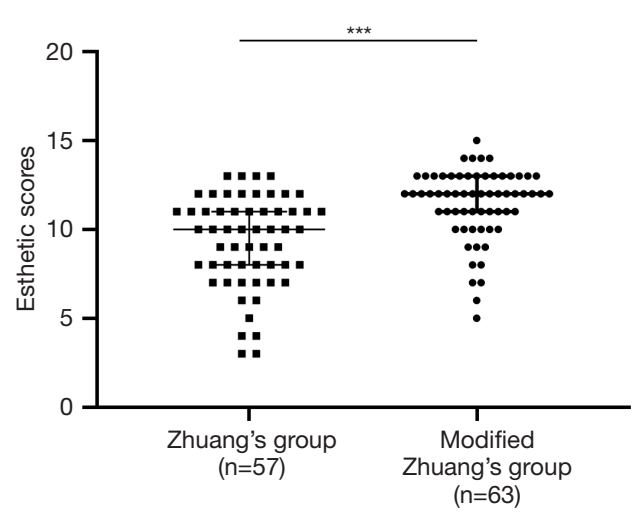

Figure 2 The average esthetic scores of two plastic surgeons. Zhuang's group: 9.5 (IQR, 7.5-11.0), Modified Zhuang's group: 11.5 (IQR, 10.5-12.5). Statistical testing: ${ }^{* * *} \mathrm{P}<0.001$.

\section{Discussion}

Total auricular reconstruction is a challenging procedure for both plastic surgeons and patients (11). Despite various methods for auricular reconstruction, no consensus has been reached as to which treatment is best (13), resulting in an ongoing effort to modify and establish new techniques, including those involving the auricular framework and envelope, with shorter treatment times, less complications, and better esthetic outcomes (4,14-16).

Several studies have focused on auricular reconstruction.
When Nagata's $(15,17,18)$ and Firmin's (19) twostage procedures became the mainstream of auricular reconstruction, skin grafting and laser epilation were the two primary defects. Afterward, Park's (8) and Zhuang's (9) tissue expander inflation technique became popular, resulting in better esthetic results because of a thinner skin flap which made the ear contour and subunit clear and vivid. Simultaneously, an expanded flap increased the postauricular hairless area, and conducting laser epilation for patients was not necessary. However, skin grafting was still necessary until Xing et al. (10) and Chen et al. (11) reported a single expanded postauricular flap without skin grafting, although this was time consuming.

We modified Zhuang's traditional method (9) by using the reformative inflation method and the remnant ear to seek an alternative method, aiming at achieving a better appearance, fewer complications, and shorter therapy time.

In the first stage, the whole pocket was in the subcutaneous layer, which is different from the traditional subfascial layer. The postauricular fascia was reserved in case of framework exposure, increasing the safety coefficient of this technique. Making the best use of remnant ear, the expander only required $60-75 \mathrm{~mL}$, decreasing the risk of expander exposure compared with traditional methods, which need approximately $140 \mathrm{~mL}$ of expander. Meanwhile, the duration of the first stage was shortened dramatically because of less saline injection, making the technique 

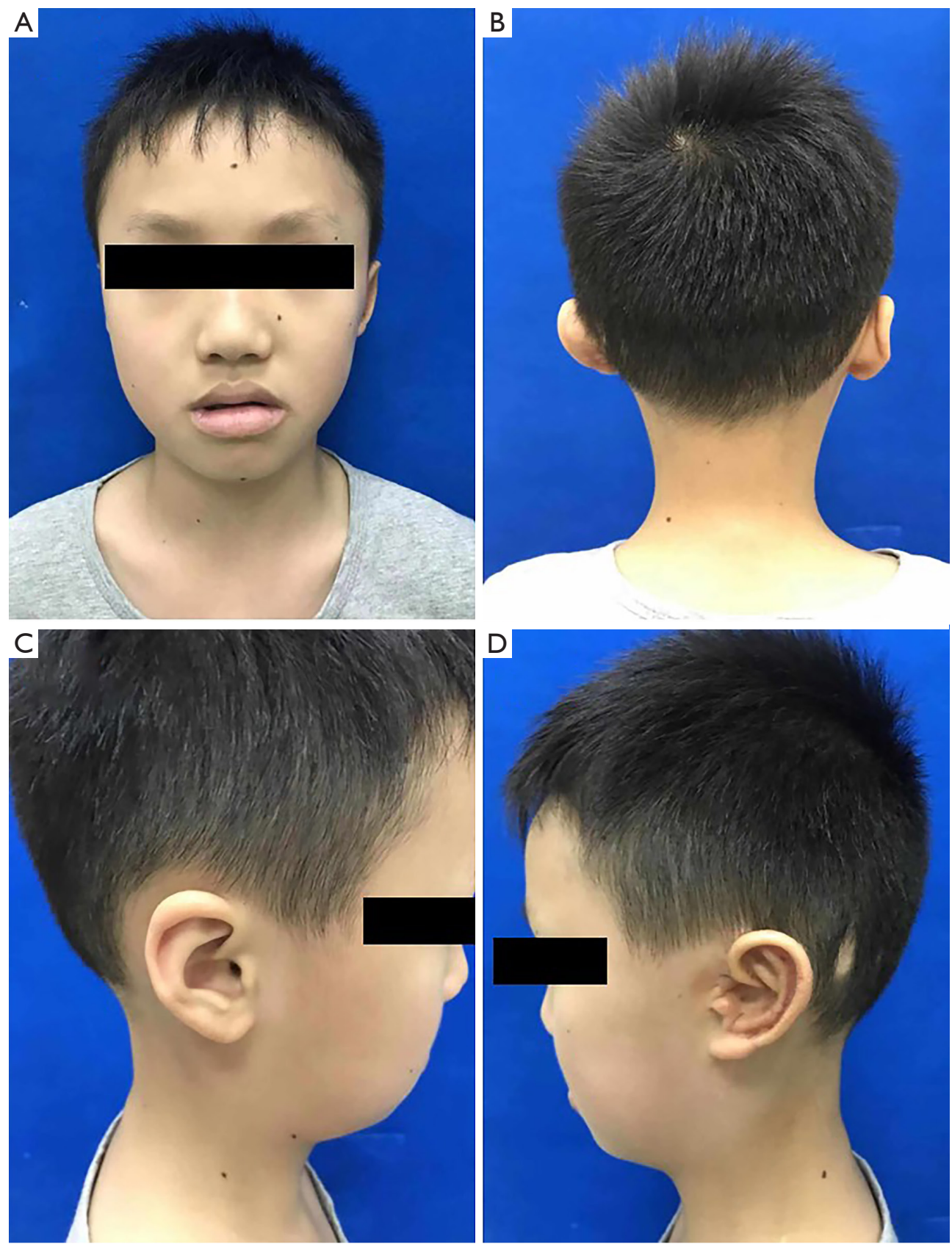

Figure 3 Case 1. A 10-year-old boy with congenital microtia on the left side. (A) Nine-month postoperative anterior view of the reconstructed ear and the symmetry of bilateral ears; (B) 9-month postoperative posterior view of bilateral ears; (C) front view of the normal ear; (D) 9-month postoperative front view of the reconstructed ear.

economical and time saving, decreasing patient suffering, and increasing patient satisfaction.

In the second stage, the expander capsule was reserved to provide proper thickness of the envelope and to decrease the risk of expander exposure, which also differs from traditional methods (7-9). Our expander insertion pocket was created in the subcutaneous layer during the firststage operation so we needed to reserve the capsule to provide proper thickness and avoid framework exposure. In addition, the retention of the capsule made fascia flap 

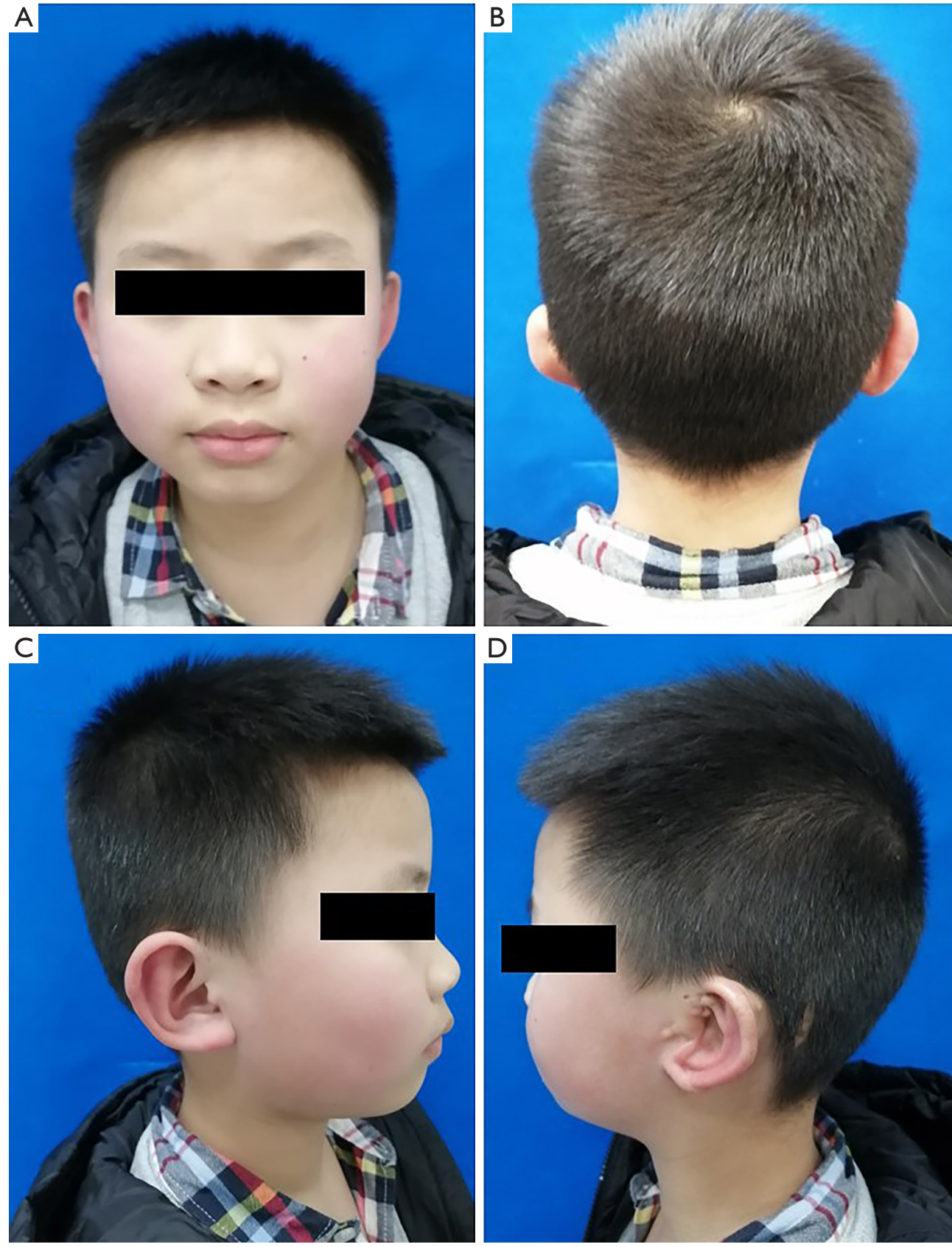

Figure 4 Case 2. A 7-year-old boy with congenital microtia on the left side. (A) Eleven-month postoperative anterior view of the reconstructed ear and the symmetry of bilateral ears; (B) 11-month postoperative posterior view of bilateral ears; (C) front view of the normal ear; (D) 11-month postoperative front view of the reconstructed ear.

transplantation an unnecessary choice in our secondstage operation, and provided a spare material for possible framework exposure, which reduced the intraoperative trauma as well as ensured thickness. Simultaneously, a good combination of loose flap and remnant ear provided additional skin tissue and decreased the force of expanded flap retraction, thereby guaranteeing a better appearance of the cranioauricular angle. As such, the possibility of local ischemia was also reduced, decreasing the occurrence of envelope necrosis or framework leakage. Meanwhile, by 

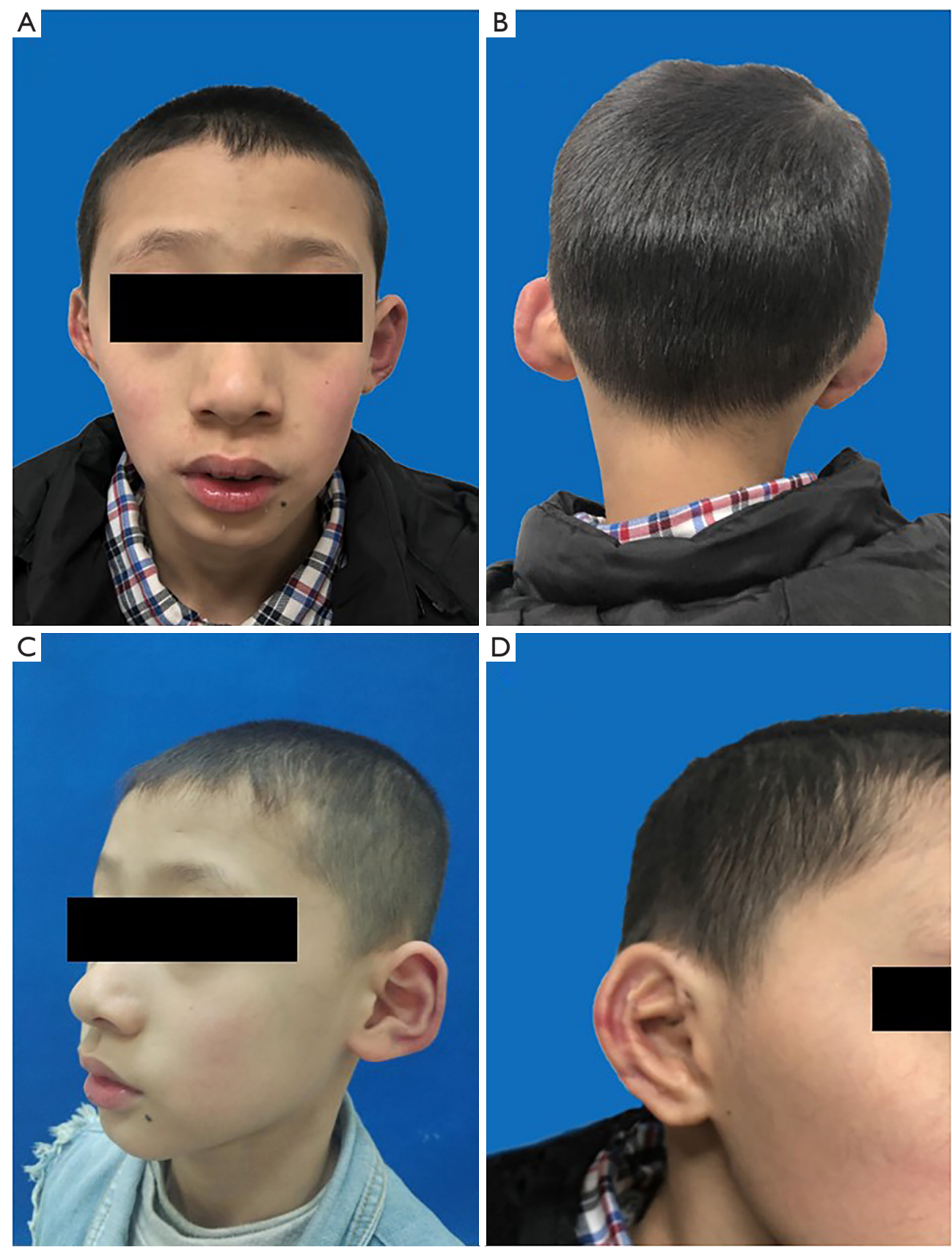

Figure 5 Case 1. A 12-year-old boy with congenital microtia on the right side. (A) Six-month postoperative anterior view of the reconstructed ear and the symmetry of bilateral ears; (B) 6-month postoperative posterior view of bilateral ears; (C) front view of the normal ear; (D) 6-month postoperative front view of the reconstructed ear.

utilizing the remnant ear skin tissue, the cavum conchae could be engraved vividly without the scruple of blood supply because the postauricular pedicle of the flap which can provide adequate blood supply is reserved. Moreover, when using the traditional Zhuang's method, there may be difficulty in deepening the cavum conchae, indicating that the modified Zhuang's method could produce a better appearance of the ear subunit at the second stage of auricular reconstruction.

Based on our results, the modified Zhuang's method 
Table 4 Complications

\begin{tabular}{|c|c|c|c|}
\hline Complication & Zhuang's group $(n=58)$ & Modified Zhuang's group ( $n=66)$ & $P$ value* \\
\hline Complications of the recipient site, $\mathrm{n}[\%]$ & 0 & 0 & \\
\hline Infection & 0 & 0 & \\
\hline Hematoma & 0 & 0 & \\
\hline Complications related with tissue expander & 0 & 0 & \\
\hline Expander leakage & 0 & 0 & \\
\hline Expander exposure & 0 & 0 & \\
\hline Complications related to second-stage period, $\mathrm{n}$ [\%] & $10[17]$ & $5[8]$ & 0.1 \\
\hline Hematoma & 0 & 0 & \\
\hline Grafted skin necrosis & 0 & 0 & \\
\hline Skin envelope necrosis & 0 & 0 & \\
\hline Frame exposure & 0 & 0 & \\
\hline Flap venous congestion & 0 & 0 & \\
\hline Cartilage absorption & 0 & 0 & \\
\hline Wire or suture extrusion & 0 & 0 & \\
\hline Hypertrophic scar & $6[10]$ & 0 & 0.024 \\
\hline Thoracic scoliosis & 0 & 0 & \\
\hline Hypertrophic scar & $2[3]$ & $2[3]$ & 1 \\
\hline Total, n [\%] & $10[17]$ & $5[8]$ & 0.1 \\
\hline
\end{tabular}

*, Pearson Chi-Square test.

provided better postoperative esthetic outcomes $(\mathrm{P}<0.001)$ and showed a lower rate of hypertrophic scar occurrence at the reconstruction site $(\mathrm{P}=0.024)$, indicating this method likely reduced hypertrophic scars and unmatched skin color because of sufficient remnant ear tissues and a stable blood supply. Moreover, our modified technique had a shorter whole therapy duration $(\mathrm{P}<0.001)$ and shorter hospital duration after operation $(\mathrm{P}=0.013)$, which relieved patients' time and financial burdens and might be related to our modified inflation method and less surgical trauma. The modified technique also had less bleeding $(\mathrm{P}=0.001)$ and less drainage $(\mathrm{P}=0.011)$, decreasing the surgical and perioperative trauma suffered by patients. In addition, no significant difference was found in complications related to the first-stage period (inflation period), indicating that the reformative inflation method could not contribute to a lower complication rate but could contribute to shorter whole therapy duration $(\mathrm{P}<0.001)$. The most likely 
Table 5 Perioperative characteristics

\begin{tabular}{|c|c|c|c|}
\hline Characteristic & Zhuang's group $(n=58)$ & Modified Zhuang's group $(n=66)$ & $P$ value \\
\hline Amount of bleeding (mL), median (IQR) & $50.0(20.0-50.0)$ & $20.0(13.5-48.5)$ & 0.001 \\
\hline Amount of drainage $(\mathrm{mL})$, mean $\pm \mathrm{SD}$ & $21.2 \pm 12.6$ & $15.9 \pm 1.2$ & $0.011^{\dagger}$ \\
\hline Hospital duration after operation (days), median (IQR) & $6(5-6)$ & $5(5-6)$ & 0.013 \\
\hline
\end{tabular}

${ }^{*}$, independent Samples Mann-Whitney $U$ test. ${ }^{\dagger}$, student's $t$ test.

complication of this method is hypertrophic scar of the recipient site, with a relatively low occurrence rate $(10 \%)$. However, it is a common disorder resulting from skin injury, which could be treated by non-surgical methods, such as laser and hormones.

Our results also showed that the duration of surgery of the modified Zhuang's method was longer $(\mathrm{P}=0.010)$, but the amount of bleeding $(\mathrm{P}=0.001)$ and drainage $(\mathrm{P}=0.011)$ were much less than that of Zhuang's method, which seems to be a paradox. The second-stage of the modified method requires time to deepen the cavum conchae and rebuild the earlobe and the tragus, which were not involved in Zhuang's method. Moreover, the dissection of the subcutaneous fascial flap and the expander capsule were not involved in the modified Zhuang's method, decreasing the degree of operation trauma, which resulted in less bleeding and drainage.

In a typical procedure, the modified Zhuang's technique is a suitable alternative technique for auricular reconstruction because of its excellent contributions to a better outline of the ear, fewer hypertrophic scar complication risks, and shorter treatment time, improving patient satisfaction and relieving the economic and physical burdens of patients with microtia.

There are several limitations to our study, the most noteworthy of which is its retrospective nature. To minimize the impact of retrospective study, we enrolled patients consecutively from July 2014 to December 2018 by a single surgeon. In addition, detailed electronic medical records and preoperative-intraoperative-postoperative photographs were reviewed. As for the limitation of the modified Zhuang's method, we still use the costal cartilage to sculpture our three-dimensional auricular framework, which leads to trauma and certain complications of the donor site. A new three-dimensional framework using biomaterials which leads to better function and a more elaborate appearance, is the key direction of our future study. Moreover, an auricular envelope with high security, less scars, and good color matching is the eternal pursuit of every plastic surgeon.

\section{Conclusions}

Our modified Zhuang's method with a single extended postauricular flap without skin grafting provides excellent results in clear contour of the reconstructed ear, matched skin color, fewer hypertrophic scars, and shorter treatment time and surgical trauma. Patients who underwent the modified Zhuang's method may also likely obtain more satisfactory results with regard to a better appearance, less suffering, and less commitment time and financial burden. Therefore, the modified Zhuang's method could be an important alternative method of treatment for patients with congenital microtia.

\section{Acknowledgments}

Funding: National Natural Science Foundation of China (Grant No. 81871574)

\section{Footnote}

Reporting Checklist: The authors have completed the STROBE reporting checklist. Available at http://dx.doi. org/10.21037/atm-21-1302

Data Sharing Statement: Available at http://dx.doi. org/10.21037/atm-21-1302

Conflicts of Interest: All authors have completed the ICMJE uniform disclosure form (available at http://dx.doi. org/10.21037/atm-21-1302). The authors have no conflicts of interest to declare.

Ethical Statement: The authors are accountable for all 
aspects of the work in ensuring that questions related to the accuracy or integrity of any part of the work are appropriately investigated and resolved. This study was approved by the ethics committee of Sichuan University [NO.: 2020(680)], and all subjects or their parents/guardians gave informed consent before surgery. All procedures performed in this study involving human participants were in accordance with the Declaration of Helsinki (as revised in 2013).

Open Access Statement: This is an Open Access article distributed in accordance with the Creative Commons Attribution-NonCommercial-NoDerivs 4.0 International License (CC BY-NC-ND 4.0), which permits the noncommercial replication and distribution of the article with the strict proviso that no changes or edits are made and the original work is properly cited (including links to both the formal publication through the relevant DOI and the license). See: https://creativecommons.org/licenses/by-nc-nd/4.0/.

\section{References}

1. Jeon B, Lee C, Kim M, et al. Fabrication of threedimensional scan-to-print ear model for microtia reconstruction. J Surg Res 2016;206:490-7.

2. Steffen A, Wollenberg B, Konig IR, et al. A prospective evaluation of psychosocial outcomes following ear reconstruction with rib cartilage in microtia. J Plast Reconstr Aesthet Surg 2010;63:1466-73.

3. Johns AL, Lucash RE, Im DD, et al. Pre and postoperative psychological functioning in younger and older children with microtia. J Plast Reconstr Aesthet Surg 2015;68:492-7.

4. Brent B. Auricular repair with autogenous rib cartilage grafts: two decades of experience with 600 cases. Plast Reconstr Surg 1992;90:355-74; discussion 375-6.

5. Fu YY, Li CL, Zhang JL, et al. Autologous cartilage microtia reconstruction: Complications and risk factors. Int J Pediatr Otorhinolaryngol 2019;116:1-6.

6. Li C, Jiang H, Huang $\mathrm{C}$, et al. A new strategy for total auricular reconstruction using prelamination of an extended retroauricular flap with tissue expansion. J Plast Reconstr Aesthet Surg 2016;69:819-826.

7. Neumann CG. The expansion of an area of skin by progressive distention of a subcutaneous balloon; use of the method for securing skin for subtotal reconstruction of the ear. Plast Reconstr Surg (1946) 1957;19:124-30.
8. Park C. Subfascial expansion and expanded two-flap method for microtia reconstruction. Plast Reconstr Surg 2000;106:1473-87.

9. Pan B, Jiang $\mathrm{H}$, Guo D, et al. Microtia: ear reconstruction using tissue expander and autogenous costal cartilage. J Plast Reconstr Aesthet Surg 2008;61 Suppl 1:S98-103.

10. Xing W, Kang C, Wang Y, et al. Reconstruction of Microtia Using a Single Expanded Postauricular Flap without Skin Grafting: Experience of 683 Cases. Plast Reconstr Surg 2018;142:170-9.

11. Chen Q, Zhang J, Wang B, et al. Total Auricular Reconstruction Using a Single Extended Postauricular Flap Without Skin Grafting in Two Stages: Experiences of 106 Cases. Aesthetic Plast Surg 2020;44:365-72.

12. Qian J, Li Z, Liu T, et al. Auricular Reconstruction in Hemifacial Microsomia with an Expanded Two-Flap Method. Plast Reconstr Surg 2017;139:1200-9.

13. Wang WS, Yan DM, Chen JY, et al. Clinical Efficacy of a Modified Nagata Method That Retains the Fascia Pedicle of the Mastoid Skin Flap in Auricular Reconstruction of Chinese Microtia Patients. Plast Reconstr Surg 2016;137:977-9.

14. Tanzer RC. Total reconstruction of the external ear. Plast Reconstr Surg Transplant Bull 1959;23:1-15.

15. Kawanabe $Y$, Nagata $S$. A new method of costal cartilage harvest for total auricular reconstruction: part I. Avoidance and prevention of intraoperative and postoperative complications and problems. Plast Reconstr Surg 2006;117:2011-8.

16. Wilkes GH, Wong J, Guilfoyle R. Microtia reconstruction. Plast Reconstr Surg 2014;134:464e-79e.

17. Nagata $S$. A new method of total reconstruction of the auricle for microtia. Plast Reconstr Surg. 1993;92:187-201.

18. Kawanabe $Y$, Nagata $S$. A new method of costal cartilage harvest for total auricular reconstruction: part II.

Evaluation and analysis of the regenerated costal cartilage. Plast Reconstr Surg 2007;119:308-15.

19. Firmin F. Ear reconstruction in cases of typical microtia. Personal experience based on 352 microtic ear corrections. Scand J Plast Reconstr Surg Hand Surg 1998;32:35-47.

Cite this article as: Zhang Y, Liu C, Wei S, Zhu G, Li Z. Clinical efficacy of modified total auricular reconstruction technique by using reformative inflation method and remnant ear without skin grafting. Ann Transl Med 2021;9(10):890. doi: 10.21037/atm-21-1302 